Egyptian J. of Nutrition Vol. XXXVI No. 1 (2021)

\title{
Serum Highly Sensitiv e C-Reactive Protein levels and its relation to dietary fiber and fat intake among medical students in the NAMES-ASU project
}

\author{
Haidy N. Louis ${ }^{\star}$ Rasha S. Hussein ${ }^{\star *}$, Nanees A. \\ Ismail** and Sahar M. Sabbour $^{* *}$ \\ ${ }^{*}$ M.B.B.Ch, Ain Shams University, Egypt \\ ** Public Health Department, Faculty of Medicine - Ain Shams \\ University.
}

\begin{abstract}
Background: Body weight, dietary fiber and fat intake are factors that influence serum level of Highly Sensitive C-Reactive protein (CRP) which is a predictor for future cardiovascular diseases.

Objectives: To describe the dietary pattern of fiber and fat intake among medical students and to assess the relation between body weight, dietary fiber and fat intake and the hs-CRP level.

Methods: A Cross Sectional study was carried out among a sample of medical students at Ain Shams University. A total of 400 medical students were involved, all participants were subjected to self-administered questionnaires including socio demographic, clinical data and 24 hours food recall and food frequency
\end{abstract}




\section{Haidy N. Louis ${ }^{\star}$, Rasha S. Hussein ${ }^{\star *}$, Nanees A. Ismail ${ }^{\star *}$ and Sahar M. Sabbour**}

questionnaire. Anthropometric measurement was done in addition to measurement of serum level of hs-CRP. Calculation of nutritional intake of fibers and fat was further analyzed using software Foods System V2 Nutri Plus, which is based on Composition of Foods.

Results: the mean age was $(21.4+1.99), 79 \%$ were females. Adequate fiber in diet was consumed by $(26.75 \%)$ of students, and $39.75 \%$ exceeded the recommended fat intake. HsCRP level was positively correlated with body weight, visceral fat and dietary fat intake and negatively correlated with dietary fiber intake. Multiple linear regression showed that female gender, body mass index, waist hip ratio, visceral fat and fiber in diet were significantly associated with hs-CRP level.

Conclusion: Increasing fiber and decrease fat intake are protective factors against increasing hs-CRP level.

Key words: CRP- fiber-body weight-students

\section{Introduction}

Highly sensitive C-Reactive Protein (CRP); an inflammatory biomarker; is influenced by many factors including socioeconomic position, genetics and diet. The inverse association between diet and hs-CRP is biologically feasible because micronutrients with antioxidative properties may enable the body to manage the balance 
Egyptian J. of Nutrition Vol. XXXVI No. 1 (2021)

between production and accumulation of reactive species that cause oxidative stress(Kuczmarski et al., 2013).

Hs-C-Reactive protein (CRP) concentration has continuous associations with the risk of coronary heart disease, ischemic stroke, vascular mortality (Kaptoge et al., 2010). Dietary guidelines from the World Health Organization and the Dietary Reference Intakes recommend $14 \mathrm{~g} / 1000 \mathrm{kcal}$ of fibersfrom the total daily calories. Diets high in dietary fiber and rich in fruits and vegetables are associated with lower hs-CRP levels, while consumption of a Western diet, a diet high in fat and refined grains, has been hypothesized to elevate hsCRP levels (Acad et al., 2014).

Obesity causes a dysregulation of multiple metabolic and endocrine pathways such as low-grade inflammation which results in chronically elevated serum concentrations of proinflammatory biomarkers (Shoelson et al., 2007). Anthropometric parameters were also correlated with inflammation. Obesity defined by body mass index (BMI) and waist circumference was associated with inflammation. Body fat, and other measures of abdominal adiposity were also positively correlated with inflammation. Furthermore, metabolic disorders might interfere with inflammatory status (DeLoach et al., 2014).

The prevalence of metabolic syndrome and central obesity increase with age, with the highest rates seen among middle-aged and older adults. Additionally, metabolic syndrome is associated with inflammation which may exacerbate the development of CVD 
Haidy N. Louis ${ }^{\star}$, Rasha S. Hussein ${ }^{\star \star}$, Nanees A. Ismail** and Sahar M. Sabbour**

(Syauqy et al., 2018). Dietary fiber includes polysaccharides, oligosaccharides, lignin and associated plant substances(AACC, 2000).

Dietary fiber is naturally present in cereals, vegetables, fruits and nuts. The amount and composition of fibers differ from food to food (Desmedt et al., 2001). Asfor the role of microbiota some studies have shown improved insulin sensitivity, weight regulation, and reduced inflammation with increases in gut-derived short-chain fatty acids, all of which may reduce the risk of developing metabolic diseases (Myhrstad et al., 2020).

Concerning fats, Dietary guidelines from the World Health Organization and the Dietary Reference Intakes recommend a total fat intake between $20 \%$ and $35 \%$ of total calories (WHO, 2010). The minimum of $20 \%$ is to ensure adequate consumption of total energy, essential fatty acids, and fat-soluble vitamins and prevent atherogenic dyslipidemia (high-density lipoprotein cholesterol (HDLC), high triglyceride-rich lipoproteins) which occurs with low-fat, high carbohydrate diets and increases risk of coronary heart disease. The maximum of $35 \%$ was based on limiting saturated fat and also the observation that individuals on higher fat diets consume more calories, resulting in weight gain (Trumbo et al., 2002).

The Institute of Medicine determined that there is no safe level of consumption of industrial trans fats from partially hydrogenated oils. Trans fats adversely affect a diverse range of 
CVD risk factors: they raise low density lipoprotein cholesterol (LDL$\mathrm{C})$, raise triglycerides, lower $\mathrm{HDL}-\mathrm{C}$, increase inflammation, promote endothelial dysfunction, and may promote hepatic fat synthesis, resulting in far greater risk of developing CHD than any other macronutrient. Based on these effects, the recommendation is to limit their intake as much as possible (Hu and Willett, 2002).

At Ain Shams university, a previous study was done to assess fruit and vegetable (F\&V) consumption among medical students, knowledge of daily requirements, perceptions of benefits, barriers and motives for (F\&V) consumption and identify their acceptance of accessible healthy food, revealed that the knowledge of the recommended five daily servings for $\mathrm{F} \& \mathrm{~V}$ was recalled by $8.2 \%$ of students, and only (23.26\%) consumed 5 servings of $\mathrm{F} \& \mathrm{~V}$ daily(Sabbour et al., 2017).

\section{Research question and hypothesis}

What is the dietary pattern of fiber and fat consumption among the medical students?

What is its relation to their HS-CRP levels?

Is there an association between obesity and visceral fat and high level of the HS-CRP?

\section{Aim/ Objectives}

The aim of this study is:

1. To describe the dietary pattern of fibre and fat intake among the medical students. 
Haidy N. Louis ${ }^{\star}$, Rasha S. Hussein ${ }^{\star \star}$, Nanees A. Ismail** and Sahar M. Sabbour**

2. To assess the relation between the dietary pattern of fibre, fat intake and the HS-CRP level.

3. To determine the relation between the body fat, the visceral fat and the HS-CRP level.

\section{Subjects and Methods}

\section{Study design and population:}

This survey was a part of the Nutritional Assessment of Medical Students of Ain Shams University (NAMES/ASU) project (Mabrouk et al., 2019). This project was designed in 2018 to evaluate the nutritional status of the undergraduate medical students aged between 17-24 years. A total number of 1225 of medical students were participated in the project. For our survey the sample size calculated by using the Epi Info 7 program for sample size calculation, assuming that $50 \%$ of students have adequate fiber intake with margin of error $=5 \%$ and at $95 \%$ confidence level. A sample size of 400 students was needed. Our sample was selected by simple random sampling technique using random number generator software from a list including all the participants after excluding participants with the following criteria

1- Self-reported chronic disease diagnosis at enrolment: angina, heart disease, chronic obstructive pulmonary disease, cancer, chronic liver disease, arthritis, diabetes (type 1 or type 2), as 
Egyptian J. of Nutrition Vol. XXXVI No. 1 (2021)

these diseases may affect dietary intakes or cause changes in the HS-CRP level.

2-Participants on omega 3 supplement or anti-inflammatory drugs as corticosteroids or smokers as this may cause changes in their HS-CRP level.

Data collection tools: All participants were subjected to the following:

1- Food frequency Questionnaire: including data: name, age, sex, study grade, past medical history and family history, main sources of fibers as fruits, vegetables, cooked vegetables and main sources of fats as meat, fish, milk eggs and trans fats from packed sweets. The quantitative food frequency questionnaire (QFFQ) was adapted from a validated food frequency questionnaire developed by the National Nutrition Institute.

2- Anthropometric measures: Weight in kilogram $(\mathrm{kg})$. Height in centimeters (cm). Body mass index (BMI). Waist circumference (WC) in centimeters (cm). Hip circumference in centimeters (cm). Waist: hip ratio (WHR)(Jelliffe and Gurney, 1974).

3- Bioelectrical impedance segmental analysis using In-Body 770: The following measurement were estimated weight $(\mathrm{kg})$, BMI, muscle mass $(\mathrm{kg})$, body fat percent (\%), fat free mass $(\mathrm{kg})$, visceral body fat, muscle mass $(\mathrm{kg})$, total body water (\%) (InBody, 770).

4- Blood test to measure serum HS-CRP $(1 \mu \mathrm{g} / \mathrm{mL})$ : analysis and CRP were measured using serum analyzer Instrumentation by ELISA. (samples was determined by interpolation from the standard curve). 
Haidy N. Louis*, Rasha S. Hussein ${ }^{\star \star}$, Nanees A. Ismail ${ }^{\star \star}$ and Sahar M. Sabbour ${ }^{\star *}$

5- Assessment of Fiber Intake and Other Dietary Variables: were done using Data of Dietary fiber intake and other dietary variables were extracted from the dietary questionnaires subjected to medical students in the NAMES-ASU project. The intake was measured using 24 food hours recall and food frequency questionnaire (Gibson et al., 2008).

6- Calculation of nutritional intake of fibers and fat was further analyzed using software which is based on Composition of Foods(F:/NUTRIPLUS/03052014NPIus/Foods.ex)

\section{Ethical approval}

An approval was obtained from the Research Institutional Board (RIB) of faculty of medicine Ain Shams University. All participating students were informed about the objectives of the project and signed a written informed consent before enrolment in the NAMES-ASU project.

\section{Data management and analysis}

Data were revised, coded, entered on computer and analyzed using SPSS package version number 25. Quantitative data were described as mean, standard deviation (SD) and range values. Qualitative data were described as numbers and percentages. Person correlation, and multiple linear regression were used to study the association between dietary fat and fibers intake, anthropometric measures, demographic and clinical characteristics of the study 
Egyptian J. of Nutrition Vol. XXXVI No. 1 (2021)

group and their serum hs-CRP level. P-value $\leq 0.05$ was considered significant.

\section{Results}

A total of 400 medical students were involved in the current study, the mean age was (21.4 \pm 1.99$), 79 \%$ were females. The maximum weight, BMI, WHR were 144.00, 46.87, 1.08 respectively.

\section{Table 1}

Only $26.75 \%$ of the students had adequate fiber in their diet in which their main sources were fruits and vegetables. Analysis of the food frequency questionnaire revealed the following: Only $15 \%$ of the students consumed 5 times or more of fruits and vegetables daily. $46 \%$ of the students met their recommended caloric requirements from fats. $14.25 \%$ of the students consumed less than $20 \%$ of their total calories from fats, $46 \%$ consumed from $20 \%$ to $35 \%$ and $39.75 \%$ consumed more than $35 \%$. Their main sources were beef, chicken, dairy products, fish, eggs and trans fats. Table 2

The association between participants' gender and their anthropometric measures, Dietary fiber and fat intake, and serum hsCRP level showed that males were more than females in the following variables, height, weight, BMI, waist circumference, hip measurements waist hip ratio, total and visceral fat in body, fat and fiber in diet and serum hs-CRP level. These differences were significant in height, weight, waist circumference, waist hip ratio, fat in diet and male gender. Table 3 


\section{Haidy N. Louis ${ }^{\star}$, Rasha S. Hussein ${ }^{\star *}$, Nanees A. Ismail ${ }^{\star *}$ and Sahar M. Sabbour**}

There were highly significant correlations between high hsCRP level and increased weight, BMl, waist, hip and WHR. Also, highly significant relations were detected between total and visceral body fat and high hs-CRP level. There was a highly significant relation between dietary fat and fiber and hs-CRP where students with high dietary fiber had lower hs-CRP, while higher dietary fat had higher hs-CRP.Table 4

Multiple linear regression showed that hs-CRP was lower in females and it was significantly higher in students with higher BMI and WHR, also it was highly significant with visceral fat and dietary fibers where CRP was higher in students with higher visceral fat and lower in students with high dietary fibers intake. Table 5

\section{Discussion}

Dietary patterns may influence cardiovascular disease risk through their effects on inflammation and endothelial activation. In this study we aimed to clarify the relation between diet and CRP level, among medical students as it's a modifiable risk factor to protect against future cardiovascular diseases. The mean age of the students in this study was $(21.4 \pm 1.99)$, most of them were females and the majority had normal weight and body mass index. Their dietary pattern revealed that Only $26.75 \%$ of the students had adequate fiber in their diet according to the WHO recommendations in which their main sources were fruits and vegetables. 
Egyptian J. of Nutrition Vol. XXXVI No. 1 (2021)

These results are in line with findings of a cross sectional study conducted among undergraduates' students in 11 faculties at Assuit University showed that $21.2 \%$ and $22.8 \%$ consume fruits and vegetables respectively several times daily although the number of daily servings was not specified (EI Ansari and Berg-Beckhoff, 2015).

Similar results that showed decreased fibers intake were found by Frank et al. (2019), in which data collected from 193,606 individuals aged $\geq 15$ years, between 2005 and 2016, as he reported that only $18 \%$ of individuals in low- and middle-income countries meet WHO recommendations consumed $400 \mathrm{~g} / \mathrm{d}$ of fruits and vegetables, which equates to $\sim 5$ servings/d. They found that the proportion of individuals meeting WHO recommendations increased with increasing country Gross Domestic Product level and with decreasing country FAO food price index, and that, at the individual level, those with secondary education or greater were more likely to achieve the recommendations than those with no formal education. A previous old analysis of representative dietary data found that fewer than 1 in 10 Americans met their fruit or vegetable recommendations (Kimmons et al., 2009).

As for fats, analysisof the food frequency questionnaire in this study revealed that $46 \%$ of the students consumed their adequate caloric needs from fats and $39.75 \%$ consumed more than $35 \%$. Their main sources were beef, chicken, dairy products, fish, eggs and trans fats. 


\section{Haidy N. Louis*, Rasha S. Hussein ${ }^{\star *}$, Nanees A. Ismail ${ }^{\star *}$}

and Sahar M. Sabbour**

A previous study by Tang et al. (2015) showed thatdietary fat can have a significant impact on overall health and metabolism. Inadequate fat intake impairs absorption of fat-soluble vitamins and leads to reduced production of hormones and lipoprotein particles, whereas excess fat can contribute to inflammation, obesity and steatosis in distal organs, for example, the liver.

Mammas et al. (2004) studiednutrient intake and food consumption among medical students in Greece assessed during a Clinical Nutrition course revealed that the contribution of total fat to energy intake was $40 \%$ in each gender. Lower fat eaters $(\leq 34.3 \%$ of total energy) had higher intakes of fiber, and fruits, and a lower consumption of red meat than students in the upper fat quartile ( $\geq 46.0 \%$ of total energy).

Concerning the relation between dietary fiber and hs-CRP level, this study showed a highly significant relation between dietary fiber and hs-CRP where students with high dietary fiber had lower hsCRP level.

Similar results were found in six clinical trials with a total of 554 individuals (192 men, 362 women) aged between (32-85) participated in the studies, reported significantly lower hs-CRP concentrations following increased fiber consumption, altered fat intakes and weight loss (North et al., 2009). 
Egyptian J. of Nutrition Vol. XXXVI No. 1 (2021)

Other similar findings by Gibson et al. (2019) among British police force employees (2007-2012) in which a dietary coding protocol for a large-scale study with 4412 participants who completed 7-day food records were included for cross-sectional analyses suggested an inverse dose-response trend between total fiber intake with body composition and inflammation. Also, Ning et al. (2013) observed a $63 \%$ lower risk of elevated hs-C-reactive protein in the highest versus lowest quartile of total fiber intake, in which a total of 11,113 subjects, aged 20 to 79 years with no history of CVD, from the 2005 to 2010 National Health and Nutrition Examination Survey were included in a study to examine associations of dietary fiber intake with predicted lifetime CVD risk and hs-CRP levels showed a highly significant relation between dietary fiber and hs-CRP.

For the fat consumption and hs-CRP level, this study showed a highly significant relation between dietary fat and hs-CRP level. On the other hand, a longitudinal study carried out by Martins et al, in the years 2014 and 2015 evaluated 408 adolescents from the municipal and state public schools between 10 and 14 years of age in which the consumption of total and saturated fats was evaluated from the 24-hour recall. The associations between concentrations of highly sensitive CRP and total and saturated fat revealed that the percentage of total and saturated fat consumption is within the recommended level in both years, with no significant difference ( $p>$ 0.05). No statistically significant associations were found between hsCRP and total fat consumption so the study did not present a significant evidence on the relationship between the concentrations of hs-CRP and the consumption of total and saturated fats. The 


\section{Haidy N. Louis*, Rasha S. Hussein ${ }^{\star *}$, Nanees A. Ismail ${ }^{\star \star}$ and Sahar M. Sabbour**}

different result may be attributed to consumption of different types of fats especially that most of the students consumed trans fats on daily basis.

As for hs-CRP level, fiber intake and body composition, few studies have investigated the associations between fiber intakes from different food sources with measures of body composition. Although the current study observed an inverse relation between dietary fibers in diet consumed by students and visceral and total body fat but the difference observed was statistically insignificant. In a large UK population sample, it demonstrated that total fiber and fruit fiber intakes are inversely associated with all measures of body composition (Gibson et al., 2019).

As for factors affecting the hs-CRP level, Correlation between hs-CRP concentrations, Anthropometric measures in this study showed a highly significant correlation between high hs-CRP level and increased weight, BMI, waist, hip and WHR. In another crosssectional study, the association between obesity in relation to serum hs-CRP levels in adults 20-70 years from October 2014 to June 2016 conducted at an outpatient Department of Medicine showed that overweight and obesity have significant correlation with hs-CRP, suggesting obesity is a state of chronic inflammation, and hence, hsCRP levels can be used in assessing future morbidity risk(Lavanya et al., 2017). 
Egyptian J. of Nutrition Vol. XXXVI No. 1 (2021)

The same results were found by Rexrode et al. (2003) in which the relationship of total and abdominal obesity with hs-CRP and IL-6 in women was studied in a cross-sectional study of 733 women free from pre-existing cardiovascular disease or cancer at baseline. BMI, WHR, and WC were all significantly correlated with CRP and IL-6, throughout the anthropometric.

Also,this study showed significant associations between fiber intake and BMI, hip measurements, in which the higher the fiber in diet the lower the BMI and hip measurements.In another study by Buscemi et al. (2018), associations between fiber intake and Body Mass Index (BMI) among African-American women participating in a randomized weight loss and maintenance trial showed no association between fiber intake and $\mathrm{BMI}$ at baseline; however, there was a significant inverse relation between fiber consumption and BMI at 6 months, and the association was even stronger at 18 months. Results from this study suggest that dietary fiber consumption may be particularly important within weight loss interventions tailored for African-American women.

Multiple linear regression in this study showed that hs-CRP was lower in females and it was significantly higher in students with higher BMI and WHR. Also, it was highly significant with visceral fat and dietary fibers where hs-CRP was higher in students with higher visceral fat and lower in students with high dietary fibers intake. Lakoski et al. (2006) showed in a data from the Multiethnic Study of Atherosclerosis cohort, a prospective cohort consisting of 6814 men and women aged 45 to 84 years recruited from 6 US communities 


\section{Haidy N. Louis*, Rasha S. Hussein ${ }^{\star *}$, Nanees A. Ismail ${ }^{\star \star}$ and Sahar M. Sabbour**}

that, women had substantially higher median CRP levels compared with men (2.56 vs $1.43 \mathrm{mg} / \mathrm{L}, \mathrm{P}<.0001)$. Meanwhile linear regression in this study showed the opposite may be due to smaller sample size and difference in age group.

Also,Firdous et al. (2006) in a pilot study among normotensive overweight and obese patients in whichthere were 34 male and 74 female patients showed that the gender-wise mean WHR did not show statistically significant difference categorized CRP levels meanwhile there was an increasing trend in CRP levels as WHR increased among females, but this was statistically insignificant $(p=0.05)$.

On the other hand,Parikh et al. (2012) in his study investigated associations of dietary fiber intake with inflammatoryrelated biomarkers and measures of total and central adiposity in a sample of 559 adolescents aged $14-18$ yr (49\% female, $45 \%$ Black), its multiple linear regression, adjusting for age, race, Tanner stage, fat-free soft tissue mass, energy intake, and physical activity, revealed that dietary fiber intake was inversely associated with fat mass in males but not in females. In both genders, dietary fiber intake was negatively associated with visceral adipose tissue, plasma hsCRP. Also Fogarty et al.reported a linear association between increase in weight and serum hs-CRP over a period of 9 years, with a $1-\mathrm{kg}$ increment being associated with an increase of $0.09 \mathrm{mg} / \mathrm{ln}$ hsCRP during this time period. 
Egyptian J. of Nutrition Vol. XXXVI No. 1 (2021)

\section{Conclusion and Recommendation}

This study indicates a need to raise awareness among medical students to consume adequate fiber in their diet as most of them didn't meet their recommended daily intake. Since it also showed that increasing the dietary fibers decreased the BMlso we recommend that dietary lifestyle modification by increasing the fiber content in diet as it has an effect on controlling increased body weight, hs-CRP level and protect against future cardiovascular diseases. 
Haidy N. Louis*, Rasha S. Hussein ${ }^{\star \star}$, Nanees A. Ismail** and Sahar M. Sabbour**

Table (1): Demographic and anthropometric characteristics of the participants $(n=400)$

\begin{tabular}{|c|c|c|c|}
\hline \multicolumn{2}{|c|}{ Demographic characteristics } & $\mathrm{N}$ & $\%$ \\
\hline \multicolumn{2}{|c|}{ Age: Mean \pm SD (Range) } & \multicolumn{2}{|c|}{$21.40 \pm 1.99(17.0-27.0)$} \\
\hline \multirow[t]{2}{*}{ Gender } & Male & 84 & $21.0 \%$ \\
\hline & Female & 316 & $79.0 \%$ \\
\hline \multirow[t]{2}{*}{ Residence } & Cairo & 288 & $72.0 \%$ \\
\hline & Other governorates & 112 & $28.0 \%$ \\
\hline \multicolumn{4}{|c|}{ Anthropometric measures Mean \pm SD (Range) } \\
\hline \multicolumn{2}{|c|}{ Height $(\mathrm{cm})$} & \multicolumn{2}{|c|}{$163.69 \pm 8.11(146-190)$} \\
\hline \multicolumn{2}{|c|}{ Weight $(\mathrm{kg})$} & \multicolumn{2}{|c|}{$66.32 \pm 14.19(40.0-144)$} \\
\hline \multicolumn{2}{|c|}{ BMI $(\mathrm{Kg} / \mathrm{m} 2)$} & \multicolumn{2}{|c|}{$24.69 \pm 4.66(16.81-46.87)$} \\
\hline \multicolumn{2}{|c|}{ Waist (cm) } & \multicolumn{2}{|c|}{$80.13 \pm 11.29(60-134)$} \\
\hline \multicolumn{2}{|c|}{ Hip $(\mathrm{cm})$} & \multicolumn{2}{|c|}{$100.58 \pm 10.07(78-173)$} \\
\hline \multicolumn{2}{|c|}{ WHR } & \multicolumn{2}{|c|}{$0.8 \pm 0.07(0.54-1.08)$} \\
\hline
\end{tabular}


Egyptian J. of Nutrition Vol. XXXVI No. 1 (2021)

Table (2): Hs-C-Reactive Protein (CRP) concentrations and dietary factors in participants $(n=400)$

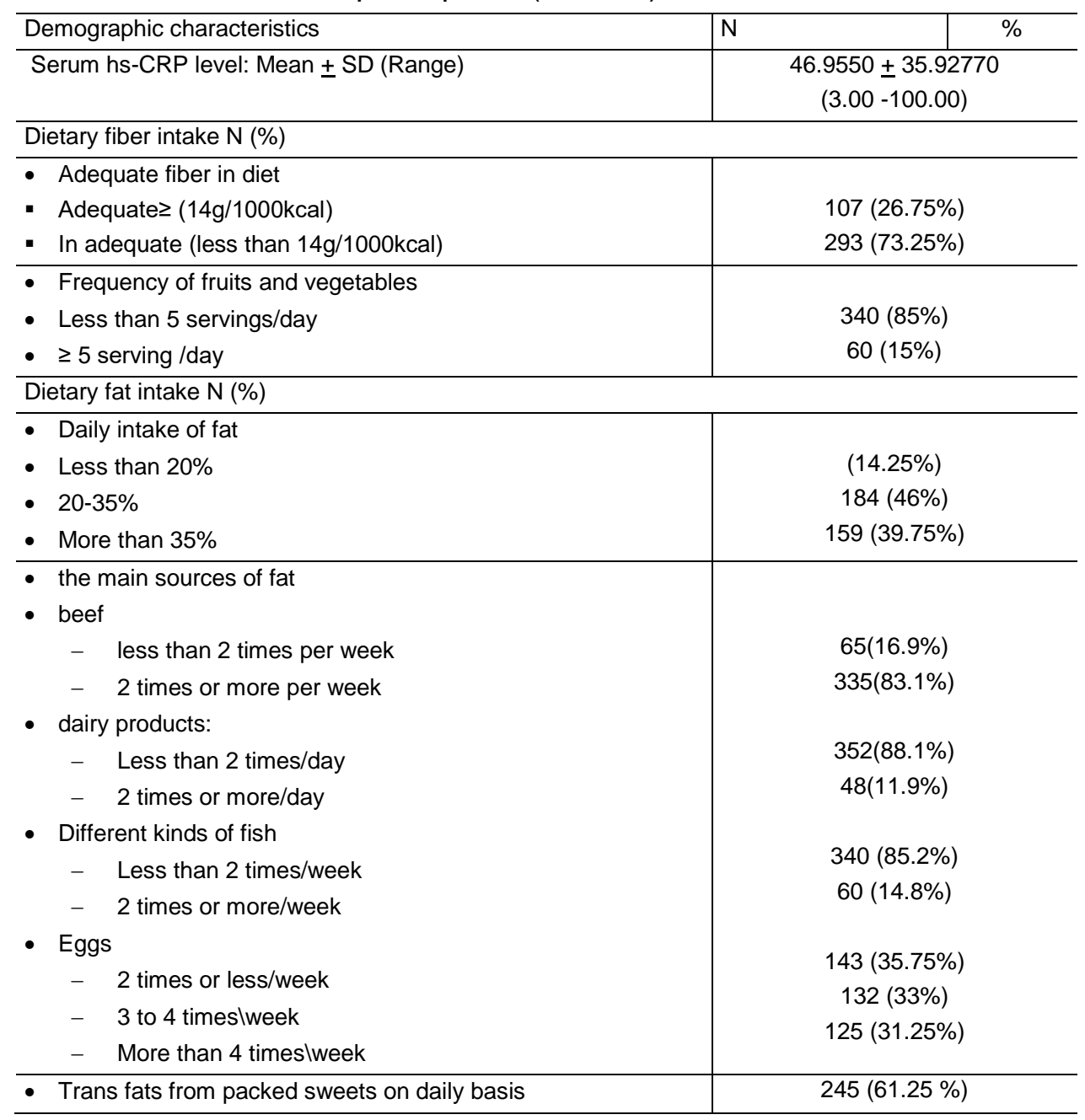


Haidy N. Louis*, Rasha S. Hussein ${ }^{\star \star}$, Nanees A. Ismail** and Sahar M. Sabbour**

Table (3):The association between participants' gender and their anthropometric measures, Dietary fiber and fat intake, and serum hs-CRP level.

\begin{tabular}{|c|c|c|c|c|c|c|}
\hline & \multicolumn{4}{|c|}{ Gender } & \multirow{3}{*}{$t^{*}$} & \multirow{3}{*}{$P$ value } \\
\hline & \multicolumn{2}{|c|}{$\begin{array}{c}\text { Male } \\
\text { N (\%) } \\
84(21 \%)\end{array}$} & \multicolumn{2}{|c|}{$\begin{array}{c}\text { Female } \\
\mathrm{N}(\%) \\
316(79 \%)\end{array}$} & & \\
\hline & Mean & SD & Mean & SD & & \\
\hline Height (cm) & 174.34 & 6.27 & 160.86 & 5.89 & 18.38 & $<0.001 *$ \\
\hline$\overline{\text { Weight (kg) }}$ & 77.09 & 14.93 & 63.45 & 12.54 & 7.68 & $<0.001^{*}$ \\
\hline$\overline{\mathrm{BMI}}$ & 25.37 & 4.86 & 24.51 & 4.60 & 1.51 & 0.13 \\
\hline Waist (cm) & 85.38 & 11.23 & 78.72 & 10.91 & 4.91 & $<0.001^{*}$ \\
\hline$\overline{\mathrm{Hip}(\mathrm{cm})}$ & 101.63 & 8.99 & 100.29 & 10.33 & 1.08 & 0.28 \\
\hline$\overline{\mathrm{WHR}}$ & 0.84 & 0.08 & 0.78 & 0.07 & 6.30 & $<0.001^{*}$ \\
\hline Total fat & 22.91 & 34.37 & 17.57 & 7.12 & 1.42 & 0.16 \\
\hline Visceral fat & 9.96 & 5.12 & 8.82 & 3.71 & 1.92 & 0.06 \\
\hline$\overline{\text { Fiber in diet }}$ & 14.83 & 13.68 & 12.76 & 6.91 & 1.34 & 0.18 \\
\hline Fat in diet & 56.44 & 25.00 & 46.22 & 22.59 & 3.60 & $<0.001$ * \\
\hline Serum hs-CRP & 54.81 & 36.40 & 44.87 & 35.57 & 2.27 & 0.02 * \\
\hline
\end{tabular}

${ }^{*}$ significant $\mathrm{p}$ value, $\left({ }^{*} P \leq 0.05\right)$ 
Egyptian J. of Nutrition Vol. XXXVI No. 1 (2021)

Table (4):Correlation between hs-C-reactive protein (CRP) concentrations, anthropometric measures and dietary factors in participants $(n=400)$

\begin{tabular}{c|c|c}
\hline & Pearson Correlation & P value \\
\hline Height $(\mathrm{cm})$ & 0.06 & 0.23 \\
\hline Weight $(\mathrm{kg})$ & 0.43 & $<0.001^{*}$ \\
\hline BMI $(\mathrm{Kg} / \mathrm{m} 2)$ & 0.46 & $<0.001^{*}$ \\
\hline Waist $(\mathrm{cm})$ & 0.38 & $<0.001^{*}$ \\
\hline Hip $(\mathrm{cm})$ & 0.40 & $<0.001^{*}$ \\
\hline WHR & 0.14 & $0.01^{*}$ \\
\hline Total body fat & 0.24 & $<0.001^{*}$ \\
\hline Total visceral fat & 0.42 & $<0.001^{*}$ \\
\hline dietary fat intake & 0.36 & $<0.001^{*}$ \\
\hline dietary fiber intake & -0.50 & $<0.001^{*}$ \\
\hline
\end{tabular}

${ }^{*}$ significant $\mathrm{p}$ value, $\left({ }^{\star} P \leq 0.05\right)$ 
Haidy N. Louis*, Rasha S. Hussein ${ }^{\star \star}$, Nanees A. Ismail** and Sahar M. Sabbour**

Table (5):Linear regression analysis for factors affecting hs-CRP level:

\begin{tabular}{|c|c|c|c|c|c|c|}
\hline & \multicolumn{2}{|c|}{$\begin{array}{l}\text { Unstandardized } \\
\text { Coefficients }\end{array}$} & \multirow{2}{*}{$\begin{array}{c}\begin{array}{c}\text { Standardized } \\
\text { Coefficients }\end{array} \\
\text { Beta }\end{array}$} & \multirow{2}{*}{ Sig. } & \multicolumn{2}{|c|}{$\begin{array}{l}95.0 \% \text { Confidence Interval } \\
\text { for B }\end{array}$} \\
\hline & $B$ & Std. Error & & & Lower Bound & $\begin{array}{l}\text { Upper } \\
\text { Bound }\end{array}$ \\
\hline Female gender & -7.179 & 3.026 & -.223 & 0.018 * & -13.129 & -1.230 \\
\hline BMI & 1.840 & .479 & .781 & $<0.001^{*}$ & 0.898 & 2.781 \\
\hline WHR & 24.697 & 11.764 & .334 & 0.036 * & 1.567 & 47.827 \\
\hline Total fat & -.060 & .096 & -.026 & 0.536 & -0.249 & .130 \\
\hline Visceral fat & 1.719 & .478 & .287 & $<0.001^{*}$ & 0.780 & 2.659 \\
\hline Fiber in diet & -1.818 & .157 & -.488 & $<0.001^{*}$ & -2.127 & -1.509 \\
\hline Fat in diet & .089 & .081 & .080 & 0.274 & -0.070 & 0.247 \\
\hline
\end{tabular}


Egyptian J. of Nutrition Vol. XXXVI No. 1 (2021)

\section{References}

American Association of Cereal Chemists (AACC) in 2000.

Buscemi, J., Pugach, O., Springfield, V, Jang, J., TussingHumphreys, S., Schiffer, L and Stolley, M. (2018): Associations between fiber intake and Body Mass Index (BMI) among AfricanAmerican women participating in a randomized weight loss and maintenance trial. Published online 2018 Feb 16. doi: 10.1016/j.eatbeh.2018.02.005

DeLoach, S., Keith, S.W., Gidding, S.S. and Falkner, B. (2014): Obesity associated inflammation in African American adolescents and adults. Am J Med Sci. 2014;347:357-63

Desmedt, A. and Jacobs, H. (2001): Soluble fiber. In Guide to functional food ingredients (pp 112-140). Instituto de la Grasa, CSIC. Avenida Padre Garcı'a Tejero, 4, 41012 Sevilla, Spain (Tel.: C34 954691054; fax: C34 954691262; e-mail: rrodri@cica.es)

El Ansari, W. and Berg-Beckhoff, G. (2015):

Nutritional Correlates of Perceived Stress among University Students in Egypt. Int. J. Environ. Res. Public Health; 12(11): 14164-14176.

FAO Food Nutr Pap. (2010):

Fats and fatty acids in human nutrition. Report of an expert consultation. 2010; 91():1-166.

Firdous, S., Lodhi, M.O. and Siddique, K. (2006):

The Trends of CRP Levels at Different Waist-to-Hip Ratios Among Normotensive Overweight and Obese Patients: A Pilot Study, PMID: 26975949. J Coll Physicians Surg Pak. 2016 Mar;26(3):191-4.

Fogarty, A.W., Glancy, C., Jones, S., Lewis, S.A., McKeever, T.M. and Britton, J.R. (2008):

A prospective study of weight change and systemic inflammation over 9 y. Am J Clin Nutr 87, 30-35. 
Haidy N. Louis ${ }^{\star}$, Rasha S. Hussein ${ }^{\star \star}$, Nanees A. Ismail** and Sahar M. Sabbour**

Frank, S.M., Webster, J., McKenzie, B., Geldsetzer, P., Manne-Goehler, J., AndallBrereton, G., Houehanou, C., Houinato, D., Gurung, M.S., Bicaba, B.W., et al. (2019):

Consumption of fruits and vegetables among individuals 15 years and older in 28 low- and middle-income countries. [Internet]. J Nutr. 2019;149(7):1252-9.

Gibson, R., Eriksen, R., Chambers, E., Gao, H., Aresu, M., Heard, A., Chan, Q., Elliott, P. and Frost, G. (2019):

Intakes and Food Sources of Dietary Fibre and Their Associations with Measures of Body Composition and Inflammation in UK Adults: Cross-Sectional Analysis of the Airwave Health Monitoring Study Received: 9 July 2019; Accepted: 4 August 2019; Published: 8 August 2019.

Gibson, R., Rosalind, S., Ferguson, Elaine L. (2008):

An interactive 24-hour recall for assessing the adequacy of iron and zinc intakes in developing countries.

Hu, F.B. and Willett, W.C. (2002):

Optimal diets for prevention of coronary heart disease. JAMA. 2002 Nov 27; 288(20):2569-78.

Jelliffe, and Gurney, (1974):

Ritional and health status, Nutrition and Growth - Page 299.

Kaptoge, S., Angelantonio, D., Lowe, G., Pepys, M., Thompson, S., Collins, R. and Danesh, J. (2010):

C-reactive protein concentration and risk of coronary heart disease, stroke, and mortality: an individual participant meta-analysis. Lancet. 375(9709): 132-140.

Kimmons, J., Gillespie, C. and Seymour, J. (2009):

Fruit and Vegetable Intake Among Adolescents and Adults in the United States: Percentage Meeting Individualized Recommendations. February 2009 Medscape Journal of Medicine 11(1):26 
Egyptian J. of Nutrition Vol. XXXVI No. 1 (2021)

Kuczmarski, M.F, Mason, M., Allegro, D., Zonderman, A. and Evans, M.K. (2013):

Diet quality inversely associated with C-reactive protein levels in urban, low-income African American and White adults. J Acad Nutr Diet.; 113(12): 10.1016/j.jand.2013.07.004.

Lakoski, S.G, Cushman, M., Criqui, M., Rundek, T., Blumenthal, R.S, Ralph, B., D'Agostino, J. and Herrington, D.M. (2006): Gender and C-reactive protein: data from the Multiethnic Study of Atherosclerosis (MESA) cohort, PMID: 16923436 DOI: 10.1016/j.ahj.2006.02.015

Lavanya, K., Ramamoorthi, K., Acharya, R. and Madhyastha, S. (2017): Association between Overweight, Obesity in Relation to Serum hsCRP Levels in Adults 20-70 Years. DOI: 10.7860/JCDR/2017/32422.11005

Mabrouk, R., Elgaafay, M., Hamza, S., ElSayed, Z., Sabbour, S., Boulos, D. and Sallam, R. (2019):

NAMES-ASU clinical nutrition first project, presented in the $40^{\text {th }}$ Annual Ain Shams University congress.

Mammas, I., Bertsias, G., Linardakis, M., Moschandreas, J. and Kafatos, A. (2004):

Nutrient intake and food consumption among medical students in Greece assessed during a Clinical Nutrition course, PMID: 14630588 DOI: 10.1080/09637480310001642448

Martins, C., Lima F. and Almeida A. (2018):

High-sensitivity c-reactive protein and total and saturated fat intake in adolescent students: a longitudinal study DOI: 10.1101/349761

Myhrstad, M.C., Tunsjø, H., Charnock, C. and Hansen, V.H. (2020): Dietary Fiber, Gut Microbiota, and Metabolic Regulation - Current Status in Human Randomized Trials. Nutrients. 2020 Mar; 12(3): 859. Published online 2020 Mar23. doi: 10.3390/nu12030859 
Haidy N. Louis*, Rasha S. Hussein ${ }^{\star *}$, Nanees A. Ismail ${ }^{\star \star}$ and Sahar M. Sabbour**

Ning, H., Van Horn, L., Shay, C.M. and Lloyd-Jones, D.M. (2014): Associations of dietary fiber intake with long-term predicted cardiovascular disease risk and C-reactive protein levels (from the National Health and Nutrition Examination Survey Data [20052010]). The American journal of cardiology. 113(2):287-91.

North, C.J., Venter, C.S. and Jerling, J.C. (2009):

The effects of dietary fibre on C-reactive protein, an inflammation marker predicting cardiovascular disease. European Journal of Clinical Nutrition volume 63, pages921-933(2009)

Parikh, S., Pollock, N.K., Bhagatwala, J., De-Huang, G., Gutin, B., Zhu, H. and Dong, Y. (2012):

Adolescent Fiber Consumption Is Associated with Visceral Fat and Inflammatory Markers. The Journal of Clinical Endocrinology \& Metabolism, Volume 97, Issue 8, 1 August 2012.

Rexrode, K., Pradhan, A., Manson, J. and Buring, J. (2003): Relationship of total and abdominal obesity with CRP and IL-6 in women. November 2003Annals of Epidemiology 13(10):674-82 DOI: 10.1016/S1047-2797(03)00053-X

Sabbour, S.M., Hussein, W.M. and Amin, G.E. (2017):

Fruit and Vegetable Consumption among Medical Students in an Egyptian University: Knowledge, Practice, and Attitude towards Accessible Healthy Food,2017. The Egyptian Journal of Community Medicine Vol. 36

Shoelson, S.E. and Herrero, L. (2007):

Obesity, inflammation, and insulin resistance. 132(6):2169-80.

Software used in food analysis:

F:/NUTRIPLUS/03052014NPlus/Foods.exe 
Egyptian J. of Nutrition Vol. XXXVI No. 1 (2021)

Syauqy, A., Hsu, C., Rau, H. and Chao, C. (2018):

Association of dietary patterns, anthropometric measurements, and metabolic parameters with C-reactive protein and neutrophil-tolymphocyte ratio in middle-aged and older adults with metabolic syndrome in Taiwan: a cross-sectional study (2018).

Tang, Y., Purkayastha, S. and Cai, D. (2015):

Hypothalamic microinflammation: a common basis of metabolic syndrome and aging. Trends Neurosci. 2015 Jan; 38(1):36-44.

Trumbo, P., Schlicker, S., Yates, A.A. and Poos, M. (2002):

Food and Nutrition Board of the Institute of Medicine, The National Academies. Dietary reference intakes for energy, carbohydrate, fiber, fat, fatty acids, cholesterol, protein and amino acids. 2002 Nov; 102(11):1621-30.

WHO, (2013):

Global Action Plan for the Prevention and Control of Noncommunicable Diseases 2013-2020 Geneva: World Health Organization; 2013. 
Haidy N. Louis*, Rasha S. Hussein ${ }^{\star *}$, Nanees A. Ismail** and Sahar M. Sabbour**

مستويات بروتين سي التقاعلي عالي الحساسية في المصل وعلاقته بالألياف

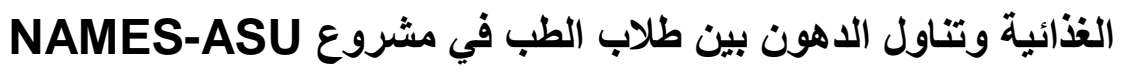

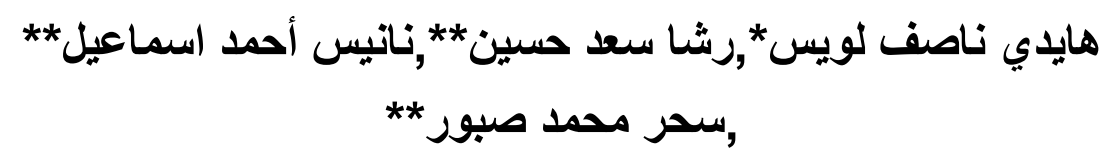

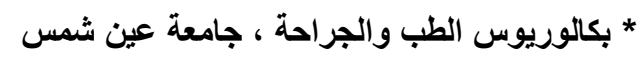

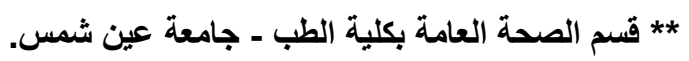

الملخص العربي

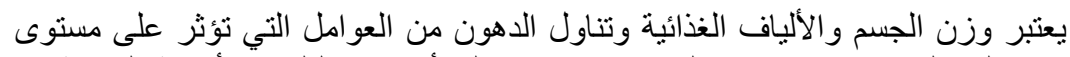

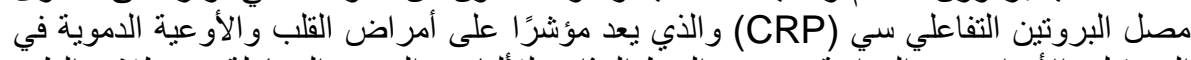

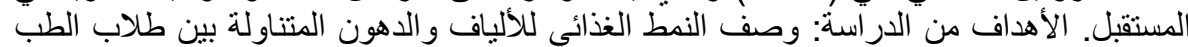

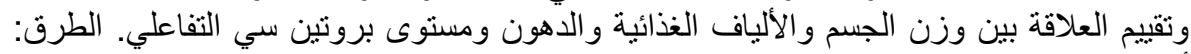

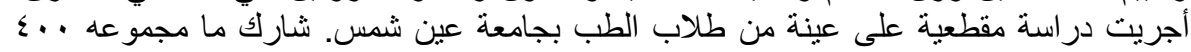

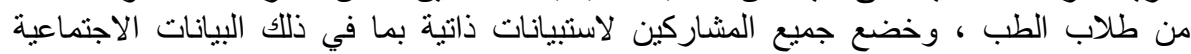

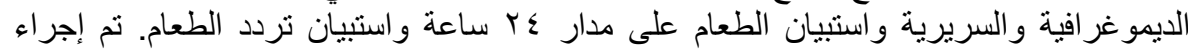

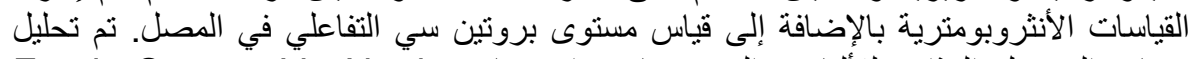

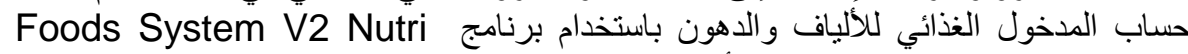

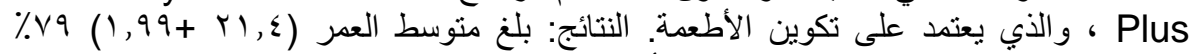

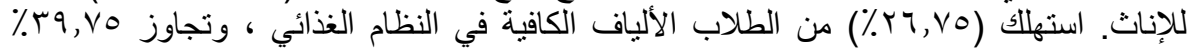

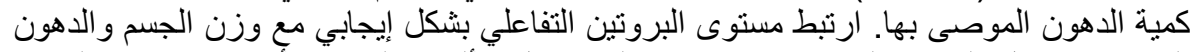

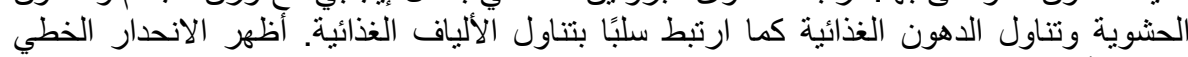

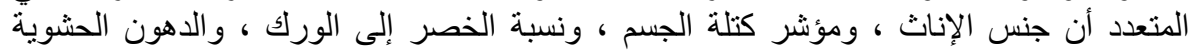

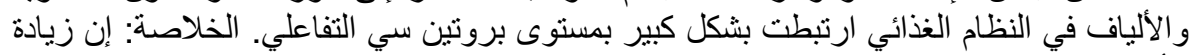

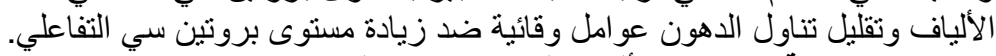

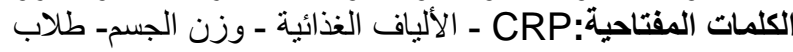

